\title{
"Mal-estar entre os ferroviários": a relação entre o Estado, a CVRD, o SINDFER e os trabalhadores de 1957 a 1961
}

"Malaise among railway workers": the relationship between the State, CVRD, SINDFER and workers from 1957 to 1961

\author{
André Ricardo Valle Vasco Pereira* \\ Douglas Edward Furness Grandson ${ }^{* *}$
}

\begin{abstract}
Resumo
Esse artigo toma o jornal do Partido Comunista do Brasil (PCB), Folha Capixaba, no período de 1957 até 1961, como base para estudar as relações estabelecidas entre o poder de Estado, a direção da Companhia Vale do Rio Doce (CVRD), o Sindifer (Sindicato dos Trabalhadores em Empresas Ferroviárias de Vitória) e os trabalhadores. Buscamos identificar as estratégias usadas por comunistas e trabalhistas como mediadores no interior desse arranjo de poder. Para tanto, discutimos com a literatura especializada e buscamos uma solução interpretativa que não seja unilateral no sentido dos mecanismos de controle ou cooptação, das dinâmicas internas das lideranças e das realidades vividas pelos ferroviários. Além disso, acompanhamos as circunstâncias mutantes de uma conjuntura complexa e rica, nas quais os atores por vezes se aliaram ou se afastaram, mas tendo sempre que dar respostas satisfatórias às pressões de suas bases e tendo em vista os limites estabelecidos.
\end{abstract}

Palavras-chave: Folha Capixaba; Sindifer (Sindicato dos Trabalhadores em Empresas Ferroviárias de Vitória); Companhia Vale do Rio Doce (CVRD).

\begin{abstract}
This paper takes the newspaper of the Communist Party of Brazil (PCB), Folha Capixaba, in the period from 1957 to 1961, as a basis for studying the relations established between the State, the Doce River Valley Co. (CVRD) board of directors, the Sindifer (Vitória Railway Workers Trade Union) and the workers. We seek to identify the strategies used by communists and laborite organizers as mediators within this arrangement. For this purpose, we discuss with the specialized literature and seek an interpretative solution that is not unilateral, nor in the sole sense of the mechanisms of control or cooptation; or the internal dynamics of the leaderships; or the realities lived by the railroad workers. In order to do so, we follow the changing circumstances of a complex and rich environment in which actors have sometimes allied or moved away, but always having to give satisfactory answers to the pressures of their bases social and in view of the limits established.
\end{abstract}

Keywords: Folha Capixaba (Capixaba Newspaper); Sindfer (Vitória Railway Workers Trade Union); Doce River Valley Company (CVRD).

\footnotetext{
"Doutor em Ciência Política pelo Instituto Universitário de Pesquisas do Rio de Janeiro (IUPERJ). Professor do Departamento de História da Universidade Federal do Espírito Santo (UFES).

** Mestre em História Social e das Relações Políticas pela Universidade Federal do Espírito Santo (UFES).
} 


\section{Introdução}

Este trabalho se debruça sobre um jornal que pertenceu ao Partido Comunista do Brasil (PCB) e foi publicado em Vitória, capital do Espírito Santo. Seu nome era Folha Capixaba. Por seu intermédio, conseguimos não só obter informações sobre as condições de vida e lutas da classe trabalhadora capixaba, como também acessamos as leituras do PCB sobre a situação. Nosso interesse, em particular, é dirigido aos empregados da Estrada de Ferro Vitória-Minas (EFVM), empresa que pertencia à Companhia Vale do Rio Doce (CVRD). Em 1942, a Vale foi criada a partir da estatização de uma empresa privada. Ela era dona de reservas de minério de ferro na região de Itabira, em Minas Gerais. Por meio da EFVM, o minério era transportado até Vitória, onde era embarcado para o exterior. Este foi o negócio da Vale até 1966, quando ela inaugurou um porto de águas profundas no complexo de Tubarão, no município da Serra, limítrofe a Vitória. Na sequência, a empresa abriu, em 1969, a primeira de uma série de usinas pelotizadoras no mesmo local. A partir daí, ela deixou de atuar apenas no transporte do minério em terras capixabas.

O Sindicato dos Trabalhadores em Empresas Ferroviárias de Vitória, Sindfer, abarcava os empregados da EFVM, mesmo os que atuavam em Minas Gerais. A Vale tinha sua diretoria no Rio de Janeiro. Em Vitória, se localizava a Superintendência da Estrada de Ferro. Em Itabira, a Superintendência das Minas. Dessa forma, todos os funcionários da empresa no Espírito Santo, inclusive os de escritório, e uma parte dos de Minas eram representados pelo Sindfer ou Sindicato dos Ferroviários, como será chamado daqui para frente por questão de simplicidade. Portanto, ao estudá-lo nas páginas do Folha Capixaba, estamos abarcando a totalidade dos trabalhadores da empresa nesse espaço geográfico citado.

Nosso foco se concentra no instante em que a entidade deixou de ser dirigida por uma diretoria perfeitamente alinhada à empresa em 1955. O que se seguiu foi uma sequência de alianças complexas entre trabalhistas, comunistas e a presidência da Vale. Foi a perplexidade dessa situação que nos levou a buscar entender o que houve. Para tanto, iniciamos com uma discussão teórica que visa entender a relação entre o Estado, dono da empresa, a própria Vale, o Sindicato e os trabalhadores em sua base. A mediação foi feita pelos grupos sindicais dirigentes, atuando em uma conjuntura marcada pelo nacionalismo e pelo reformismo, que foi se radicalizando ao longo do 
período. Daí a passagem para uma discussão específica sobre populismo e trabalhismo. Passamos, então, a análise empírica.

\section{Mecanismos de controle dos trabalhadores e a ação das lideranças}

Ao abordar as relações estabelecidas entre classe trabalhadora, empresariado e Estado, algumas interpretações entram em conflito através do enfoque dado à ação dos indivíduos. Por um lado, uma visão que contempla o forte papel da ideologia como persuasor de uma das partes da relação, mantendo seu controle. Por outro lado, um determinado grupo agiria apenas quando um grau de insatisfação econômica chegasse a um ponto inaceitável, que geraria a ação política, espontaneamente. Alternativa a essas concepções, a noção de que existe a escolha individual frente a uma estrutura de possibilidades exige que se estabeleça melhor o que é uma reprodução ideológica e o que é uma escolha ou apropriação ideológica dos indivíduos. É preciso também levar em conta o que não é intencional e o que é intencional (PEREIRA, 2015). E devemos ter em mente que o campo econômico não determina o campo político, sendo importante o papel das lideranças agindo na organização de um grupo que busca determinados objetivos em comum. Esse ponto remete ao embate do estruturalismo ou funcionalismo e o racionalismo, ou campo da ação individual. André Pereira (2013a) identificou, para o caso dos ferroviários da Companhia Vale do Rio Doce (CVRD), em 1948, mecanismos internos e externos de controle dos trabalhadores, sendo, respectivamente: a) regras internas à empresa, por meio da distribuição de incentivos coletivos e seletivos entre seus funcionários, de modo a impor uma sociabilidade por ela idealizada $^{1}$, com vistas a romper a solidariedade horizontal entre os trabalhadores; e b) instituições geradas a partir do Estado Novo e sobreviventes no regime democrático que vigorou de 1945 até 1964, envolvendo um sindicalismo corporativo, voltado para a prestação de serviços aos seus associados, numa relação de dependência e controle por parte do Ministério do Trabalho (e suas Delegacias Regionais do Trabalho nos estados), da Justiça do Trabalho (e suas Juntas de Conciliação e Julgamento locais) e dos meios

\footnotetext{
${ }^{1}$ Como forma de atrair os funcionários para sua forma de sociabilidade, a CVRD lançava mão de relações tradicionais e modernas com os trabalhadores, articulando-as conforme a situação. A partir disso, gerava uma gama de estímulos que visavam atrair os trabalhadores para ganhos individuais, "vestindo a camisa da empresa", desestimulando a ação coletiva dos trabalhadores. Ao funcionário bem relacionado com seus superiores, com uma ficha funcional sem registros, os ganhos eram mais fáceis, e aqueles que recorressem e se alinhassem a chefias em casos de registros nas fichas, poderiam ter benefícios. Os que eram questionadores, não alinhados às chefias, eram eliminados do quadro da empresa ou não tinham acesso aos benefícios disponíveis.
} 
repressivos abertos, como as Delegacias de Ordem Política e Social (DOPS), que, entre outras coisas, ofereciam os "atestados de ideologia" como permissões para a inscrição nas disputa de chapas sindicais. Se os problemas de relação extrapolavam a vida interna da empresa, fora dela havia instituições para conciliá-los e julgá-los. Essa opção de observar os meios de controle e a ação individual visa suprir as faltas que uma visão estruturalista comete com relação a mecanismos que estimulam os indivíduos a agirem de dado modo, tornando-os meros reprodutores passivos das relações sociais. Segue uma breve exposição de duas interpretações que, a seu modo, incorrem em dificuldades relacionadas ao que foi dito.

Maria Cecília de Souza Minayo, em seu livro De ferro e flexíveis: marcas do estado patrão na subjetividade operária, fez um estudo sobre os trabalhadores da CVRD em Itabira, Minas Gerais, na área de extração de minério. Neste, a autora identificou o crescimento da hierarquização da empresa, que havia nascido rudimentar na época dos 'leões da Vale’ (1942-52), se complexificando com a introdução de novas maquinarias (1952-72), gerando mudanças substanciais nas relações de trabalho na empresa. Além disso, a autora chega a identificar mecanismos de coação aos trabalhadores, como: promoções dirigidas, favorecimentos a trabalhadores "fiéis" em detrimento de outros, superexploração do trabalho, arbitrariedades de feitores e chefias, etc. A autora, porém, colocou, no plano explicativo, a ideologia nacionalista acima desses elementos como fator fundamental no processo de disciplinarização dos empregados. Mesmo que estivessem insatisfeitos, argumenta Minayo, o pensamento de que estariam se sacrificando pelo seu país, pelo seu povo, gerava uma adesão acrítica ao ideário exposto pela empresa (MINAYO, 2004). Outro ponto a ser considerado é que a autora só entrevistou trabalhadores que concluíram suas carreiras na empresa ou que ainda estavam exercendo suas atividades profissionais nela. Minayo não teve acesso aos que questionaram o processo de disciplinarização, pois, provavelmente, já haviam sido demitidos ou mesmo se afastaram quando ela fez sua pesquisa de campo. Com isso, ela não teve acesso aos movimentos de resistência, aos esforços de organização autônoma dos trabalhadores e à aplicação efetiva dos mecanismos utilizados para que fossem tolhidos. Seu olhar se concentrou nos que aquiesceram. Entre eles, de fato, Minayo encontrou um papel relevante para o nacionalismo, tendo em vista o período abordado por este trabalho, como instrumento de adesão às hierarquias e controles internos.

Outro autor que estuda o processo de disciplinarização da classe trabalhadora é Ruy Braga (2010). Em seu livro, A política do precariado, discorre sobre os sistemas 
de produção implantados no Brasil, assim como as formas estabelecidas de regulação do trabalho. No seu entendimento, dentro do sistema fordista periférico, implementado no país a partir da década de 1940, a forma de mediação entra capital e trabalho era populista. Posteriormente, dentro do mesmo sistema de produção, a regulação populista ${ }^{2}$ se esgotou, e adotou-se a mediação autoritária com a Ditadura Militar. Na virada dos anos 1990, deu-se a passagem para o que ele chama de "pós-fordismo" como forma de padronização do sistema produtivo. A implantação de um modelo "flexível", e não mais especializado, de ocupação laboral, teve consequências no papel exercido pelos sindicatos, que se viram forçados a agir de acordo com as pressões do novo mercado de trabalho, em busca do conceito de "empregabilidade". Por fim, Braga identifica a regulação lulista, forma de relação por fora dos sindicatos, para atender àquela parcela da população que conceitua como precariado. Essas são as pessoas que não gozam dos direitos trabalhistas de forma permanente e estável, com baixo ou nenhum grau de especialização e submetidas às formais mais brutais tanto de comando quanto de execução de tarefas ocupacionais.

Ao longo de sua argumentação, Braga nos fala de uma classe trabalhadora dividida entre os setores especializados e os precarizados. Os últimos seriam particularmente caracterizados por um permanente "inquietação operária”. No caso do populismo, a principal fonte de pressão sobre os sindicatos vinha do precariado. Na regulação pós-fordista, a precarização se ampliou para o seio mesmo dos setores mais especializados, aumentando a competição e conflito entre os trabalhadores e dificultando a construção da solidariedade de classe. Já sob o lulismo, houve uma aproximação das condições de vida dos trabalhadores precarizados e do subproletariado. Os que conseguem emprego formal por fases e são periodicamente expulsos para o mercado informal, o subemprego ou desemprego vivem em condições próximas aos mais miseráveis, atendidos pelas políticas sociais dos governos do Partido dos Trabalhadores (lulismo). No caso da discussão que está sendo feita aqui, o problema se encontra na relevância que o autor dá aos setores precarizados e sua permanente inquietação, localizada abaixo de um nível mais sólido de organização consciente.

\footnotetext{
${ }^{2}$ A forma de regulação populista defendida por Ruy Braga concebe os sindicatos como mediadores das relações entre a classe trabalhadora e o Estado. A base operária pressionaria seus representantes, que pressionariam, por sua vez, o Estado, obtendo retornos materiais. Desse modo, uma relação de apoio pautada nos retornos materiais faria da classe trabalhadora apoiadora do representante populista. Nessa relação, segundo a interpretação de Ruy Braga, a classe trabalhadora apenas reagiria com insatisfação e movimentos espontâneos, recorrendo à estrutura corporativista. Essa relação, portanto, se daria de maneira vertical, Estado-sindicatos-trabalhadores.
} 
Perde-se de vista aqui, como em Minayo, as resistências, a forma como foram derrotadas, e o lugar efetivamente ocupado pela organização consciente da classe trabalhadora. A abordagem de Braga é relevante por dirigir o foco para o precariado e nos ajudar a observar uma das fontes da insatisfação, que não poderia ser ignorada. A literatura que Braga critica, ou seja, a sociologia do trabalho mais "tradicional", muitas vezes enxergou os sindicatos, atores de uma estrutura corporativa, e suas bases operárias "aristocráticas" como parte de uma engrenagem de poder e controle eficientes, dando pouco espaço para as reações de base. Nesse sentido, o que vale ser questionado é se a fonte exclusiva da inquietação se encontrava nos setores precarizados e se uma inquietude, uma "pulsão plebeia" na linguagem do autor, era o máximo a que conseguiam chegar.

Este é um estudo sobre os ferroviários da CVRD. A referência a Minayo é inescapável não só pelo fato dela ter estudado a empresa (em Itabira, na área de extração de minério, sem incluir a Estrada de Ferro Vitória-Minas, EFVM), como pelo lugar de relevância que sua obra possui na literatura especializada. Braga, por sua vez, alcançou um destaque recente nos debates acadêmicos, com a revisão que fez dos estudos anteriores e com sua interpretação inovadora. Um aspecto importante da leitura dos dois são os olhares, respectivamente, para dentro da empresa (Minayo), e para as relações externas à mesma (Braga). $\mathrm{O}$ que se defende aqui é que os mecanismos criados tanto dentro quanto fora da empresa geraram cálculos por parte dos indivíduos que se apresentaram como lideranças dos trabalhadores, tanto nos sindicatos como em partidos ou grupos menos estruturados. Tais lideranças tinham que ultrapassar os obstáculos citados para reduzir os custos da ação coletiva de suas bases e oferecer perspectivas de ganhos, a partir das reivindicações concretas envolvendo os trabalhadores. Isto significa que eles atuaram em arenas estruturadas, com escolhas possíveis, com assimetria de recursos, que os forçaram a fazer escolhas, a realizar cálculos e tomar atitudes. Em termos analíticos, isso nos remete a um debate sobre a escolha racional.

Segundo Octávio Ianni (1991), a década de 1970 forneceu às Humanidades uma renovação em resposta ao avanço do positivismo, que tentara pautar as Ciências Humanas pelas Naturais. Uma dessas abordagens alternativas foi a do individualismo metodológico ou a teoria do cálculo racional. Nessa concepção, a interpretação é importada da teoria econômica com vistas a observar o comportamento individual frente a determinadas estruturas e conjunturas. Foi o caso de Adam Przeworski (1989) e Mancur Olson (2000). O primeiro deu importância ao papel da liderança frente ao ato 
de organizar um grupo. As escolhas que os indivíduos ou grupos fazem surtem efeitos nos resultados, destes e de seus competidores, na busca de um interesse público em disputa. O segundo se aprofunda na questão organizativa, demonstrando que, em um grupo latente, muito amplo, é necessária uma ação externa para estimular a ação coletiva e com isso favorecer a obtenção de ganhos públicos para o grupo. Angelo Panebianco (2005), por sua vez, tratando de organizações partidárias, desenvolve esse aspecto do raciocínio que está sendo considerado aqui. Segundo o autor, reformulando a lei férrea de Michels (1982), o papel do líder remete a uma eficácia que é dependente da distribuição de incentivos coletivos e seletivos, dentro e fora do partido ou organização. Se um grupo é organizado, ele não age apenas por sua conta. De fato, está inserido em um campo no qual há outros atores, com os quais pode entrar em disputa ou se aliar. Tendo em vista tal característica de interação estratégica, cabe pensar a contribuição de Jon Elster (1989).

Segundo o autor, a teoria do cálculo racional recebe o amparo da teoria dos jogos, que tem por característica colocar agentes racionais, com interesses divergentes ou convergentes, em interação. O jogo, nesse caso, é um instrumento analítico que deve ser desenhado pelos pesquisadores. Há situações de interação estratégica (jogos) nos quais, por exemplo, os ganhos são disputados de forma que a perda de um dos envolvidos representa ganho para o outro (soma zero). Não é o caso de, aqui, aprofundar sobre diferentes modelos de jogos. O que queremos enfatizar é a situação mais realista das interações humanas, nas quais os atores agem tendo em vista o que é chamado de "informação imperfeita", ou seja, se envolvem em jogos nos quais um ou mais de seus participantes não conhece os recursos dos outros, as informações das quais dispõem e sua habilidade para processá-las. Desse modo, a construção de estratégias ganha em complexidade, acentuando, justamente, o lugar das lideranças.

Nós abrimos a discussão interpretativa chamando a atenção para mecanismos internos e externos de disciplinarização da classe trabalhadora. Abordamos, depois, dois autores que os consideram de forma separada e enfatizam seu impacto. Mas pensamos que há um processo de mediação entre os trabalhadores e os que operam os meios de poder (internos e externos). Isto nos conduziu a uma pequena discussão sobre a escolha racional, muito mais com o propósito de destacar a relevância das lideranças sindicais, partidárias, ou de grupos mais ou menos informais no ambiente de trabalho, do que de aprofundar o debate interpretativo nesse campo. O que queremos dizer é que, na relação entre o Estado, a empresa (CVRD), o Sindicato dos Ferroviários e os trabalhadores, 
encontramos não só a atuação das máquinas de poder como também a intervenção de indivíduos que se colocaram como elites dirigentes de classe, atuando num plano competitivo, tendo que dar respostas, de um lado, às formas de controle, de outro, à pressões e insatisfações dos assalariados.

Antes de passar à análise empírica propriamente, faremos algumas considerações sobre os termos populismo e trabalhismo, não só pela referência feita por Ruy Braga ao primeiro termo como modo de regulação, mas também pela necessidade de localizar o plano ideológico de forma mais precisa no nosso recorte temporal.

\section{Populismo Vs. Trabalhismo}

O termo populismo foi muito utilizado no Brasil para identificar a relação estabelecida entre o governo Vargas e a classe trabalhadora. O principal argumento é o de que, manipulada pelo líder carismático, a população era enganada e entregava a nação nas mãos de demagogos, ineficientes e desonestos. A origem desse tipo de discurso advém do antivarguismo, de seus adversários liberais, marcados pelo elitismo e pela convicção de que o povo não sabe votar (BENEVIDES, 1984). Um autor marxista, para não restringir a questão à direita liberal, que defendeu essa concepção, foi Francisco Weffort (2003), que enfatizou o aspecto repressivo e voltado ao controle dos trabalhadores do Estado varguista. Sua leitura foi relativizada por uma corrente estabelecida por Angela Maria de Castro Gomes (2010), em seu livro pioneiro, A invenção do trabalhismo. Ali, ela oferece uma resposta alternativa para o entendimento da questão. Em primeiro lugar, a autora não utiliza o termo populismo por considerá-lo inadequado. Em segundo lugar, através da teoria da dádiva de Marcel Maus, contrapõe a essência desse conceito tal qual vinha sendo considerado.

Segundo Gomes (2010), Vargas e sua assessoria, a partir de 1942, deram efetivamente andamento ao projeto de poder que visava manter a ditadura estado novista. A entrada do Brasil na II Guerra entrou nos cálculos políticos da assessoria de Vargas, que prognosticava um conjunto de pressões com o término do conflito para a redemocratização do país. Para enfrentar essa questão, a ação foi criar uma base de sustentação do governo, constituída pelos trabalhadores. Para efetivar isso, colocou nos ministérios do Trabalho, Indústria e Comércio (MTIC) e Justiça a figura de Alexandre Marcondes Filho. Este, bem relacionado com o empresariado paulista, faria com que a legislação do trabalho fosse cumprida, assim como daria formatação final às leis 
trabalhistas, consolidadas, em 1943, com a CLT. Esses ministérios eram importantes exatamente pela necessidade de efetivar a legislação, e dar uma demonstração aos trabalhadores do compromisso de Vargas com eles. Nesse ponto entra a teoria da dádiva ${ }^{3}$. Seguindo Marcel Mauss, a autora percebeu que Vargas criou um laço com os trabalhadores, efetivando a legislação trabalhista em uma relação de reciprocidade. Desse modo, os trabalhadores teriam que retribuir ao presente com o apoio e a defesa de um projeto. Desde a década de 1930 esse tipo de relação foi estabelecido, mas com um enraizamento público definitivo na década seguinte com o uso do nacionalismo. Este, diferente daquele presente na $1^{\mathrm{a}}$ República, destacava, para além das riquezas nacionais, o homem brasileiro, entendendo que sua valorização, educação e auxílio o fariam central para o desenvolvimento do país. Desse modo, como foi observado nos discursos semanais de Marcondes Filho no programa de rádio Hora do Brasil, o trabalhador era colocado sempre no centro do desenvolvimento do país. Vargas seria aquele que "deu" a legislação trabalhista, valorizando o assalariado brasileiro. Esse projeto foi feito com base em pautas históricas do movimento sindical desde o início do século $\mathrm{XX}$, mas apresentado como iniciativa de Vargas num processo de apagamento do passado de lutas operárias. Porém, dentro da estrutura corporativa e com um projeto nacionalista, os trabalhadores encontraram um espaço possível para as suas lutas. Nem determinado, nem ilimitado, mas calculado dentro de uma "estrutura econômica, política e ideológica" (PRZEWORSKI, 1989). Observando a relação estabelecida entre Vargas e a classe trabalhadora através da teoria da dádiva, tem-se que levar em conta que "darreceber-retribuir" são momentos indispensáveis para a criação e para a manutenção do vínculo. Desse modo, quem recebe e retribui pode cobrar e pressionar aquele que comumente dá, assim como ocorre por parte do que oferta. Desse modo, os trabalhadores não eram atores passivos, e sim racionais, no sentido de que havia uma pauta colocada pelo "modelo populista de regulação", centrada na efetivação das leis trabalhistas, sua extensão aos trabalhadores do campo, na unificação da previdência social, no avanço do nacionalismo na forma de empresas estatais que explorassem riquezas nacionais, etc.

\footnotetext{
${ }^{3}$ A teoria de Marcel Maus se refere a uma relação marcada pela reciprocidade, que em si, é desigual. O trinômio dar - receber - retribuir seria o cerne da relação. Um indivíduo com um poder maior que o outro daria a este um presente, que este teria que receber. Feito esse primeiro momento, é estabelecido um vínculo entre os dois e se exige a retribuição do que Maus chamou de gift. A relação não é apresentada como interessada, pois a noção de que se cria um laço de reciprocidade dá o invólucro para a relação. Não receber o presente significa não estabelecer os laços, e por sequência, a desobrigação da retribuição. Por isso Gomes identifica que Vargas tinha interesse em fazer valer a legislação trabalhista, para que esta fosse apresentada como um gift aos trabalhadores, que retribuiriam ao ato.
} 
Ocorre, porém, que o projeto de Vargas teve que tomar outros rumos, haja vista a pressão da oposição pela redemocratização, sendo forçado pelas circunstâncias a dar andamento ao processo eleitoral. O trabalhismo, que seria a base da continuidade do regime de Vargas, se tornou um partido, seguindo um plano B da assessoria do ditador. O Partido Trabalhista Brasileiro (PTB) representou esse projeto e buscou manter a ligação com a classe trabalhadora através dos sindicatos. As relações estabelecidas entre o Ministério do Trabalho e os sindicatos mantinham a comunicação entre os polos da relação, garantindo a "correia de transmissão" entre o Estado e a classe trabalhadora (lembrando que Braga concebe essa conexão também de baixo para cima).

Jorge Ferreira (2005) demonstrou que, no segundo governo Vargas, a relação entre Ministério do Trabalho e o PTB se intensificou. João Goulart, presidente da legenda, se tornou o titular da pasta em substituição a Segadas Viana. Vargas trocou suas peças para dar resposta a um dilema político, pois o segundo agia com forte truculência policial e o governo perdia apoio dos trabalhadores, resultando em relativo enfraquecimento do PTB. A entrada de Goulart reformulou os termos das relações entre Estado e classe trabalhadora, assim como fortaleceu a legenda. O novo ocupante do cargo tinha por característica dialogar com a classe trabalhadora, recebendo as lideranças sindicais e dando retornos aos reclamos operários, ofertando ganhos reais aos trabalhadores, assim como incentivando a fiscalização destes junto às Delegacias Regionais do Trabalho e às Juntas de Conciliação e Julgamento. Em 1953, convocou o Congresso da Previdência Social. Mas, segundo Ferreira, isso não significava uma dominação de tipo manipulatória do MTIC sobre os trabalhadores, pois ele concebe o trabalhismo na linha de uma interpretação thompsoniana da história, ou seja, tendo em vista a construção de uma cultura de classe. Angela de Castro Gomes havia chamado a atenção para as origens do trabalhismo varguista do tipo reformista com base em um dos projetos que circulava no movimento sindical antes dos anos 1930.

Jorge Ferreira vê no trabalhismo a expressão política de uma cultura de classe. O problema desse argumento é o de não levar suficientemente em conta a diferença entre as elites dirigentes trabalhistas e suas bases. A classe trabalhadora brasileira, na passagem dos anos 1950 para 1960 se encontrava, como nos diz Przeworski, em um processo de organização, para o qual várias lideranças se apresentavam, como trabalhistas, comunistas, socialistas e cristãos progressistas. No caso da nossa pesquisa, usamos um jornal que pertencia ao Partido Comunista do Brasil (PCB) como fonte primária para estudar a relação entre o Estado, a CVRD, o Sindicato dos Ferroviários da 
Estrada de Ferro Vitória-Minas e os trabalhadores. Foi possível perceber que trabalhistas e comunistas disputavam a representação sindical. Ao contrário da divisão muito específica entre empregados com funções mais especializadas e outros, desqualificados, na linha de Ruy Braga, notamos a insatisfação geral dos ferroviários da CVRD, à qual comunistas e trabalhistas buscavam dar voz, representar e organizar para a ação. Nesse sentido, se envolveram em cenários de interações estratégicas que resultaram, por certas vezes, em alianças, por outras, em enfrentamentos.

O pano de fundo discursivo no qual os atores se colocaram foi o do nacionalismo e da onda reformista que começou a se formar no fim dos anos 1950 e cresceu no início dos 1960. A CVRD, como bem demonstra Minayo, usou o nacionalismo como meio de persuasão e ele ficou bem registrado na memória dos empregados daquela fase que foram entrevistados por ela. Seu formato era o seguinte: a Vale é uma empresa estatal, que pertence ao povo. Ela extrai minério, que é uma riqueza da Nação, transporta e vende ao exterior. O país lucra com isso e reverte o ganho em benefício dos brasileiros como um todo. Dessa forma, os funcionários da CVRD cumpriam com o papel de contribuir para o desenvolvimento do país. Devemos ter em mente que a autora também cita os benefícios materiais que a empresa distribuía, como o emprego formalizado, com carteira assinada, o pertencimento a um sindicato organizado, prestador de serviços, assim como seu Instituto de Aposentadorias e Pensões. Sem falar nas promoções, bônus, escolas para os filhos dos empregados, habitação. $\mathrm{O}$ acesso a tais vantagens era seletivo e usado pela empresa com o fito de disciplinar sua mão de obra, incutir uma adesão aos seus valores e atacar as formas coletivas autônomas de organização que surgiam no seu interior. Sabemos disso por meio de trabalhos variados sobre a Vale (AMARAL, 2014; BERTOCCHI, 2014; PEREIRA, 2014) e, também, pela comparação com o caso da Fábrica Nacional de Motores (RAMALHO, 1989), que seguiu caminho semelhante. De qualquer forma, o nacionalismo esteve presente e teve sua relevância. Em Minayo, ele foi usado pela empresa. Vamos notar, porém, que elites dirigentes disputaram essa bandeira, buscando dar-lhe significados que fossem instrumentais em seu esforço para representar interesses. Se o nacionalismo e o cumprimento da pauta deixada pelo Estado Novo (funcionamento efetivo das leis trabalhistas, sua extensão, ampliação da previdência social, etc.), consubstanciada no reformismo que foi se radicalizando na conjuntura estudada, foram tão relevantes, isso se deveu tanto ao seu uso "ideológico" (no sentido do convencimento, de cima para baixo) quanto no significado simbólico que eles 
adquiriram junto à classe trabalhadora. É nesse sentido que vale a pena distinguir o trabalhismo como linha política de uma cultura de classe que enxergou sua identidade nesses elementos. Assim, eles estavam disponíveis e foram disputados, tanto pelas máquinas de poder, internas e externas, quanto pelos que se apresentaram como elites dirigentes dos trabalhadores. Essa história é menos linear do que possa parecer numa abordagem mais geral e um dos objetivos deste trabalho é o de demonstrá-lo para o que prosseguimos em direção à parte empírica.

\section{"Mal estar entre os ferroviários"}

Em linhas gerais, o recorte da pesquisa perpassa três gestões do Sindicato dos Ferroviários da EFVM: 1956-57, 1958-59, 1960-61. Ele aponta para algumas conjunturas distintas. As duas primeiras gestões foram marcadas pela aliança PTB PCB, mudando na terceira (1960-1961), quando o PTB se isolou na diretoria. De início, houve uma aliança entre essas lideranças e a direção da CVRD, representada por Francisco de Sá Lessa, seu presidente, até a segunda gestão (1958-1959), quando se deu uma ruptura, percebida pelos discursos da linha editorial do jornal. Inicialmente, ele prestava apoio integral à aliança sindical e elogiava a direção da CVRD. Depois passou a criticar ferrenhamente Sá Lessa. Paralelo a isso, na coluna "Escreve o trabalhador", várias críticas foram endereçadas à direção da entidade com relação à falta de cobertura em problemas mais concretos dos ferroviários. A tônica do ataque se concentrou na acusação de que os dirigentes sindicais estavam mais antenados em pautas amplas da sociedade, recebendo críticas de sua base, prejudicadas por problemas cotidianos. As pautas cobertas pelo jornal no que se refere ao Sindicato lidaram com os seguintes temas: nacionalismo, previdência social, aumento salarial e a volta dos demitidos na greve de 1948. Já no que se refere às condições de vida e trabalho dos ferroviários, o Folha Capixaba se concentrou na demanda por um Hospital Ferroviário; na melhora do atendimento da entidade que funcionava como prestadora de previdência e assistência da categoria, a CAPFESP (Caixa de Aposentadoria e Pensões dos Ferroviários e Empregados em Serviços Públicos); na manutenção de benefícios que estavam sendo retirados pela empresa (gêneros alimentícios e lenha); na luta contra a exploração do trabalho e arbitrariedades patronais; além da cobrança de que houvesse intervenção do Sindicato no sistema de "promoções pingadas", que beneficiavam mais uns funcionários que outros. 
É perceptível a diferença entre a quantidade e qualidade das pautas. Apesar dos sindicalistas buscarem aumentos salariais e a volta dos demitidos, várias eram as críticas relativas a outros problemas que, vale observar, estão ligados aos mecanismos de controle e quebra de solidariedade entre os trabalhadores criados pela $\mathrm{CVRD}^{4}$. O que será observado neste artigo são quatro questões a partir do que foi exposto acima: 1) a estratégia dos atores dentro da estrutura possível de ação; 2) o aparecimento dos mecanismos externos de coerção; 3) o cálculo individual dos atores nas conjunturas, e 4) o debate das lideranças sindicais sobre questões colocadas pelo Estado, com o fito de garantir um espaço de autonomia.

Para abordar a primeira questão, vamos oferecer algumas informações sobre as diretorias do Sindicato dos Ferroviários. Em uma entrevista feita com um dirigente do PCB/ES, Antonio Ribeiro Granja (GOMES, 2006), foi possível traçar um perfil das direções da entidade a partir dos anos 1940. Em 1944, o PCB conseguiu eleger Manoel Cipriano Pinto como presidente. Daí para frente, em três mandatos consecutivos, o partido apenas apoiou chapas. Em 1952, foi eleito José Clímaco Goes, que se apresentava como inimigo dos comunistas. Granja (2012) destacou que a empresa sempre atou no sentido de influenciar nas eleições sindicais. Em certos momentos, como em 1951, houve mesmo confluência entre o PCB e a CVRD. Em 1955, Etevany Ferraz foi eleito presidente pela primeira vez (assumiu em 1956), tendo dirigido a entidade por três mandatos seguidos. Ele era filiado ao PTB. Já Alcyr Correia da Silva, do PCB, ingressou na diretoria como primeiro secretário (GRANDSON, 2016) e lá permaneceu até 1959. Em 1961, ele foi eleito presidente. Depois, foi reeleito e preso pelo Regime Militar.

É possível que Etevany tenha sido vereador no município de Nova Era, em Minas Gerais, pois seu nome consta de um histórico da Câmara e a localidade era servida pela EFVM (HISTÓRIA, 2017). Já em 1958, Alcyr foi candidato a deputado estadual, no Espírito Santo, pelo PTB (TRIBUNAL SUPERIOR ELEITORAL, 1961, p.

\footnotetext{
${ }^{4}$ Os mecanismos internos de controle eram regras criadas pela empresa, que produzia um discurso legitimador apoiado na legislação do trabalho, mas que não necessariamente condizia com ela. Com esses, e alternando ações tradicionais e modernas, a direção distribuía incentivos seletivos aos funcionários que se enquadrassem no padrão idealizado pela empresa, do funcionário impecável, eficiente e obediente. A diferença de tratamento gerava um incentivo a ação individual por parte dos funcionários, pois os incentivos coletivos distribuídos pelas lideranças operárias encontravam nos recursos que a empresa detinha grande dificuldade na redução dos custos da ação coletiva de sua base. Dar benefícios para um e não para outro, punir um e o outro não, através de um discurso tradicional e moderno, conforme a necessidade do caso, marcava esses mecanismos internos de controle, como foi observado por Pereira (2013b).
} 
175). Houve, nesse momento, portanto, uma aproximação entre os dois atores, o PTB e o PCB.

Em uma coluna do Folha Capixaba, intitulada "Vida Sindical", de 1957, foi publicado um texto elogioso tanto à direção da CVRD, quanto aos diretores do Sindicato dos Ferroviários. No segundo ano do mandato de Etevany Ferraz e Alcyr Correia da Silva (1956-57), a coluna apontava para uma gestão diferenciada ao afirmar: "Quem conheceu anteriormente o sindicato dos ferroviários não diz o que é atualmente [...]", pois, à sua frente, estavam "ETEVANY FERRAZ, homem de envergadura e desassombrado e que foi muito bem escolhido pelos seus colegas; em segundo plano temos o Sr. ALCYR CORREIA DA SILVA, podemos considerá-lo como ídolo dos operários da Cia. Vale do Rio Doce". Segundo o texto, até a diretoria da CVRD reconhecia o valor da diretoria sindical, se referindo à consideração do "ilustre amigo Professor Francisco Sá Lessa, mui Digno presidente da Cia. Vale do Rio Doce S/A". Desse modo, orgulhavam-se os ferroviários de estar de "mãos dadas com o capital e o trabalho" (FARIA, 1957, p. 4).

Essa aliança é notada em outra matéria, mas de forma menos harmoniosa. Em matéria do jornal, foi descrita uma situação embaraçosa para os trabalhadores. Uma festa para eles, feita no Clube dos Ferroviários e bancada pelos trabalhadores, teve uma disponibilidade de gêneros reduzida, deixando os participantes desconcertados com a falta de alimentação. A isso se somou que eles deram um presente caro ao presidente da CVRD, um "luxuoso carro", mas, vale observar, sem o consentimento dos empregados. Junto a uma festa sem muito glamour, o presente ofertado em homenagem a Francisco de Sá Lessa, pago com o dinheiro dos trabalhadores, gerou um "Mal estar entre os ferroviários” (MAL ESTAR, 1957, p. 2). Segundo a reportagem, os funcionários nem reclamaram do fato de presentear Lessa, mas o problema é que foram descontados de maneira forçada na folha de pagamentos, sem consulta e sob coerção em alguns casos, tendo ocorrido a ameaça de inserção do nome de reclamantes e recalcitrantes na ficha de serviço $^{5}$. A iniciativa de ocupantes de altos cargos da Vale é que gerou esses embaraços, pois tentaram "trazer cortesia com o chapéu dos outros" (MAL, 1957, p. 2). Nesse ponto, a menção aos sindicalistas Etevany Ferraz e Alcyr Correia foi justificada pela matéria, sendo a contribuição destes de caráter estritamente pessoal. Deve ser observada

\footnotetext{
5 A ficha de serviço era onde as faltas, licenças, suspensões, advertências e outros eventos eram registrados. Para um trabalhador da CVRD, ter um registro na ficha de serviço não era interessante, pois podia perder benefícios ou ter menos compreensão em caso de acidente com prejuízos materiais. Isso porque o que constava em ficha servia de pesagem para punições.
} 
a questão. Primeiro, a acusação a uma comissão de altos funcionários que havia organizado a festa, tirando a responsabilidade do presidente da empresa que, implicitamente, merecia o presente e não seriam contrários a isso os trabalhadores, fosse feito de outra maneira. Segundo, a isenção do aspecto institucional da participação dos líderes sindicais no evento. Por último, a confirmação de que havia uma relação de proximidade entre a direção da empresa e a diretoria do sindicato. A CVRD, segundo o discurso de Alcyr Correia, "a cuja está à frente esta figura magnífica de administrador que é o engenheiro Sá LESSA, é um motivo de orgulho para nós" (REALIZAÇÃO, 1957, p. 5), é mais um indício da aliança entre as direções.

Após a reafirmação da chapa sindical Etevany-Alcyr, em 1958, eleita com 3.066 votos contra 366 da chapa concorrente, o discurso do petebista se referiu a essa aliança, justificando que a proximidade com a direção da empresa em nada geraria prejuízos nas lutas dos trabalhadores (VITÓRIA, 1957, p. 7). Isso mostra sua lógica através do aparecimento do segundo ponto a ser destacado por este trabalho: os mecanismos de coerção. No segundo ano do mandato de 1958-1959, as relações entre a direção da empresa e sindical ficaram mais difíceis, e a postura elogiosa do Folha Capixaba em relação a Lessa se alterou substancialmente. Um primeiro evento a ser destacado é o pedido de aumento pela direção sindical. Ao contrário de outros momentos em que a negociação se deu de forma mais ágil, a resistência da empresa em conceder o acréscimo foi grande, sendo necessária a mediação do governo federal. Houve o aumento salarial de $30 \%$ após muitas manobras da empresa para não conceder o reajuste. Logo após, uma circular interna da CVRD informou aos seus trabalhadores que não haveria promoções naquele ano, haja vista que os $30 \%$ fariam extrapolar os acréscimos salariais. Ou seja, após ser dado o aumento, por meio de uma regra interna da empresa, um direito dos trabalhadores foi retirado, como que em represália à conquista. E outro ponto a observar é que houve um aumento a nível federal para todos os servidores, sendo, portanto, seu evento na CVRD um desdobramento disso e não uma negociação feita a nível regional. A partir de então, as negociações entre empresa e sindicatos passaram a ser mediadas pelo Ministério do Trabalho, como foi em 1960, quando o Sindicato fez outro pedido de aumento salarial frente à feroz inflação que o Brasil enfrentava (SANTANA, 1960, p. 6).

Com isso, nota-se que a aliança feita entre a liderança sindical e a direção da CVRD foi estratégica. A base sindical do PTB no Espírito Santo não era muito sólida. O partido, em si, estava sob o controle de lideranças coronelistas (CARDOSO, 2014). A 
ascensão de Etevany se deu ao longo do tempo. Da mesma forma, após a greve de 1948, o PCB sofreu um duro processo de perseguição por parte da empresa. Segundo o depoimento de Antonio Granja, entre 1952 e 1955, o Sindicato foi comandado por José Clímaco Goes, com apoio da Vale e da DRT. Para derrotá-lo, trabalhistas e comunistas se uniram. Essa aliança foi explicada pelo dirigente com a seguinte expressão: "é que, aí, nós já estávamos em desgraça" (GRANJA, 2012, p. 60). Ou seja, não havia condições de competir com uma chapa pura de comunistas e nem de enfrentar abertamente o comando da empresa.

Nesse ponto, chamamos a atenção para a disputa pela bandeira do nacionalismo, que citamos na parte teórica. Minayo nos mostrou o uso do nacionalismo pela empresa. Da mesma forma, trabalhistas e comunistas buscavam se apropriar desse elemento simbólico, porém oferecendo os conteúdos de acordo com seu projeto. Momentaneamente, numa situação de interação estratégica, quando as insatisfações cresceram entre os empregados da CVRD, deu-se uma aliança entre a direção da empresa e lideranças sindicais trabalhistas e comunistas. Logicamente, houve ajustes entre as partes que resultaram em benefícios mútuos. A aliança alimentou uma proximidade e o controle das reivindicações. Porém, como nos chama a atenção Ruy Braga, há uma constante inquietude operária, com base não exatamente na situação dos precarizados, mas das condições concretas de vida dos trabalhadores de uma forma geral. Para tanto, o Sindicato não podia simplesmente fechar os olhos. Isso levou a um rompimento com o comando da empresa. Nesse caso, porém, ao "queimar" um dos elos da relação Estado-Empresa-Sindicato-Trabalhadores, o que restou? Apelar diretamente ao Estado.

Quando a aliança com a empresa se encerrou, as máquinas externas de poder é que passaram a processar os pedidos de aumento salarial e outras demandas. Como já dito, a linha editorial do jornal seguiu o fim da aliança e passou a criticar o presidente da CVRD. Dentro de um clima de polarização ideológica gerada pelo aumento da influência norte-americana no Brasil, os comunistas passaram a acusar o governo de Juscelino Kubitschek de aproximação com interesses estrangeiros, e, dentro desse contexto, a recepção de executivos do Export-Import Bank of the United States (Eximbank) no Espírito Santo, para analisar a Estrada de Ferro Vitória-Minas e sancionar um empréstimo, gerou críticas do jornal a Sá Lessa. Além da "subserviência aos gringos", o presidente tratara os trabalhadores com "preconceitos sociais" $(30 \%$, 1959, p. 1). Assim, ele passou de nacionalista e amigo dos trabalhadores a subserviente 
ao estrangeiro e preconceituoso com os trabalhadores. A aliança sindical-empresarial estava desfeita ali, e os mecanismos externos de controle passaram a atuar. A mudança de configuração das alianças no jogo levou os trabalhistas e comunistas a ressignificarem sua leitura do nacionalismo, claramente exposta no tratamento da figura de Sá Lessa.

O nacionalismo nos leva ao terceiro aspecto a ser observado, que é a estratégia dos indivíduos nas conjunturas. Em 1958, dois dirigentes comunistas estavam presentes nas colunas do Folha Capixaba, apelando para um discurso nacionalista. André Pereira (2013a; 2014) demonstrou que houve uma greve na CVRD em 1948, com um forte grau de autonomia dos trabalhadores frente às instituições do Estado. Após argumentar que o dissídio coletivo não seria aprovado na Justiça do Trabalho, formou-se uma Comissão de Salários a partir da base, com direção política do $\mathrm{PCB}$, que não tinha acesso à direção do Sindicato por conta do controle exercido pelo governo Dutra. O discurso elaborado pela Comissão apontou para a necessidade de auto-organização dos trabalhadores e de solidariedade para que atingissem seus objetivos. $\mathrm{Na}$ onda de demissões que se seguiu ao fim da greve, foram envolvidos Geraldo Paulino e Lourival Coutinho.

A orientação do PCB, em 1948, após a cassação dos mandatos federais do partido, foi a de estimular uma onda de greves, a partir das condições de vida dos trabalhadores, com o objetivo de disseminar a sua nova linha política. Ela passou a tratar o governo Dutra como uma ditadura fascista, aliada aos Estados Unidos e contra os interesses nacionais. É nesse sentido, por exemplo, que o forte apelo pela campanha em defesa do petróleo e do ataque aos "trustes", ou seja, às empresas multinacionais, passou a ter prioridade. Ocorre, porém, que a fala da Comissão de Salários passou longe do propósito de mobilizar os ferroviários e conduzi-los à adesão ativa à linha política: fazer greve; atacar o Estado; defender o petróleo; combater empresas estrangeiras; combater os "coronéis", que delas eram aliados; e lutar pela paz contra o imperialismo norte-americano. Isso não foi feito porque as condições concretas não permitiram. $\mathrm{O}$ tipo de configuração vigente no enlace Estado-Empresa-Sindicato-Trabalhadores, mediado pelas elites que se apresentavam como dirigentes dos assalariados, não ofereceu meios para tanto. O governo Dutra havia assumido, desde 1947, não só um ataque direto ao PCB como um afastamento com relação a Getúlio Vargas e o seu PTB. Os trabalhistas perderam espaço no MTIC e muitos chegaram a sofrer perseguições policiais no movimento sindical por conta de certa confusão que o aparelho repressivo estabeleceu entre eles e os comunistas. A virada conservadora do governo Dutra levou o 
PCB a fazer uma leitura radical, combativa do nacionalismo. A CVRD acompanhou esse processo e optou também por uma linha altamente repressiva. O componente Estado-Empresa da equação, a máquina externa e interna de poder, se combinaram para enfrentar o PCB como dirigente sindical, num momento no qual o PTB não tinha forte presença entre os ferroviários. Naquelas circunstâncias, o máximo que o PCB conseguiu fazer no Espírito Santo foi debater a sua linha política fora da CVRD. Dentro da EFVM, a inquietação operária foi usada pelo partido para justificar um processo político de luta com base nas condições concretas de trabalho.

No fim da década de 1940, no Espírito Santo, havia uma Campanha do Petróleo organizada (GRANDSON, 2014), assim como a presença de um truste no setor de energia elétrica, a Companhia Central Brasileira de Força Elétrica (C.C.B.F.E.), propriedade da Amforp, sediada nos Estados Unidos da América (JOELSONS, 2014). As condições políticas gerais para apelar aos ferroviários podiam encontrar elementos nas condições concretas, mas isso não foi feito. Na prática, o PCB estabeleceu um corte entre a ação na empresa e fora dela. Já em 1958, a atitude foi outra, pois a configuração do jogo se tornou diferente. Isso ficou perceptível nos discursos de Lourival Coutinho e Geraldo Paulino no Folha Capixaba. O primeiro deixa implícita uma visão elogiosa sobre Sá Lessa. Segundo ele, o fato da direção ser composta por brasileiros e não subordinada a norte-americanos se deu "graças a gloriosas lutas dos ferroviários juntamente com o apoio do movimento nacionalista que empolga o Brasil" (COUTINHO, 1958, p. 5).

Geraldo Paulino, por sua vez, se referiu às eleições que ocorreram naquele ano. Fazendo propaganda contra Carlos Lindenberg, o candidato do Partido Social Democrático (PSD) ao governo do estado, lembrava o evento de 1948, em que ele, exercendo seu primeiro mandato como governador, tratou os ferroviários com truculência policial, à base de pancadaria. Dessa forma, exortava os votos no PTB, e identificava como traição aos trabalhadores quem votasse de forma diferente. Segundo ele: "Votar nos candidatos do PTB é contribuir para a causa dos trabalhadores e reforçar o movimento nacionalista" (PAULINO, 1958, p. 3). É bom lembrar que Alcyr Correia da Silva estava disputando uma vaga de deputado federal pelo PTB.

Por fim, passamos a abordar o tema da busca de autonomia ou, pelo menos, de um maior espaço de negociação no interior do laço Estado-Empresa-SindicatoTrabalhadores. No terceiro mandato de Etevany Ferraz, que havia cindido sua aliança 
com Correia e vencido por pequena margem as eleições de $1959^{6}$, a questão da Previdência Social gerou um debate sobre a administração do órgão. Estamos falando de um momento histórico no qual as Reformas de Base como pauta unificadora dos trabalhadores ganhava ímpeto. A unificação da Previdência Social foi um legado do Estado Novo, que havia criado o sistema de Institutos por categoria organizada. O tema foi discutido em vários momentos. Em matéria de 4 de fevereiro de 1961, o Folha Capixaba fez um histórico desse debate, ao citar o I Congresso de Previdência Social, em 1946; a posterior Conferência Sindical de Previdência Social, em 1953; e alcançando ao ano de 1961, com a promulgação da Lei Orgânica da Previdência Social. Chegou-se, segundo o texto, em um ponto avançado dessa luta, porém, o semanário, assim como movimentos sindicais, acusavam a tentativa do Estado em atrelar a Previdência a um Ministério, o que excluiria os trabalhadores da participação na constituição da instituição e sua gestão (EM PERIGO, 1961, p. 3). Portanto, seguindo o rastro das discussões feitas no jornal, percebe-se que as direções sindicais dos trabalhadores não estavam alheias aos mecanismos de controle do Estado e, mesmo que certos temas fossem direcionados pelo governo federal, elas estavam atentas ao domínio deste em seus assuntos, buscando construir um espaço de autonomia. É bom lembrar que o jornal do PCB estava se referindo à participação dos ferroviários nesse debate, em um momento no qual o partido se encontrava fora do comando do Sindicato. Isso não impediu, então, que fossem limitadas diferentes arenas, de forma semelhante à 1948, quando o PCB fez um discurso para a Sociedade sobre sua linha política e outro para a base sindical de ferroviários. O desentendimento entre PTB e PCB no pleito sindical de 1959 não impediu que o jornal dos comunistas reconhecesse o papel jogado pelo Sindicato dos Ferroviários na luta maior em torno da Previdência Social, que teria, caso tivesse sido vencedora, ampliado o espaço de intervenção das direções sindicais, em nome de uma autonomia dos trabalhadores na gestão do órgão.

\section{Considerações finais}

A Companhia Vale do Rio Doce foi uma das maiores empresas do Brasil e, certamente, a mais importante do Espírito Santo. Marta Zorzal e Silva (2004) estudou a sua trajetória e demonstrou como ela conseguiu se autonomizar, de maneira relativa,

\footnotetext{
${ }^{6}$ Ao todos foram 4.130 votos, distribuídos em: "Etevany 1.598 votos, Alcyr 1.348, José Coradine 1.184" (ELEIÇÃO, 1959, p. 8).
} 
com relação ao governo federal. A Vale servia ao importante propósito de exportar minérios, conseguindo carrear moeda forte para os cofres do Tesouro Nacional, em um momento no qual as necessidades do processo de industrialização, tal qual se deu, no formato de uma modernização conservadora, implicava em gastos pesados com importações, remessas de lucros e empréstimos.

Desde o início, a empresa participou de um mercado internacional fortemente competitivo. Os aportes necessários para que ela atuasse com eficiência nem sempre foram obtidos com muita facilidade, o que implicou no recurso a estratégias internas de contenção de gastos. Entre elas, o controle dos salários e, ao mesmo tempo, o aumento da produtividade dos empregados. Tudo isso se deu numa conjuntura de fortes pressões inflacionárias.

Tanto o trabalho nas minas quanto na estrada de ferro exigiam enorme esforço físico e exposição a riscos, que implicaram num volume ainda não quantificado de acidentes de trabalho. As difíceis condições laborais e os ganhos sempre abaixo da inflação se somavam ao que Ruy Braga chamou de "despotismo das chefias", ou seja, a forma brutal de tratamento e, mais importante, as estratégias de concessão seletiva de benefícios, de forma a combater a solidariedade horizontal entre os empregados. Tais aspectos foram chamados aqui de "máquina interna de poder".

O processo de formação da classe trabalhadora urbana brasileira não deve ser entendido apenas com base nos controles que as "máquinas externas de poder", inseridas no Aparelho de Estado, implicaram. E nem somente nos dilemas e limitações das suas elites sindicais ou partidárias dirigentes. O que nós defendemos é a necessidade de levar em conta o conjunto dos instrumentos de poder tal como foram mediados pelas elites dirigentes de classe em circunstâncias dadas, concretas, nas quais vigiam fortes assimetrias de recursos materiais e simbólicos disponíveis aos trabalhadores e os que se propunham a constituí-los como classe, na linguagem de Adam Przeworski.

A conjuntura que se abriu em 1955, com a eleição de Etevany Ferraz para a presidência do Sindfer, e que foi encerrada com o Golpe de Estado de 1964, nos mostra a complexidade de arranjos que precisaram ser elaborados para dar respostas tanto aos esquemas de controle e disciplinarização quanto à inquietação operária de base. A comparação com o que houve em 1948 é relevante para demonstrar o aprendizado que houve por parte das direções sindicais.

Quando o PCB se viu excluído da ordem institucional, tomou a decisão de exigir dos seus militantes de base nos sindicatos que comandassem greves e aproveitassem as 
mobilizações para "conscientizar" a classe trabalhadora, de forma a constituir um amplo movimento de massas em defesa de suas pautas. No caso do Espírito Santo, o que houve, na prática, foi uma separação das duas arenas, com a Comissão de Salários dialogando com sua base em termos das condições reais de luta, enquanto seus militantes atuavam fora da empresa no sentido de defender a linha política. Foi isso que demonstrou Marlon Pittol de Oliveira (2014) quando estudou os discursos do comunista Hermógenes Lima Fonseca, que ocupava uma vaga de vereador em Vitória, em 1948. A mesma pessoa teve destacado papel na Folha Capixaba ao longo de todo o período de estudo, assim como a mesma publicação abriu espaço para dois militantes comunistas que estiveram na Comissão de Salários.

Em 1958, Geraldo Paulino e Lourival Coutinho estavam nas páginas da Folha Capixaba defendendo um discurso nacionalista e reformista, apelando diretamente aos ferroviários, aos quais se dirigiam pelo jornal na condição de companheiros de profissão. O que houve entre um momento e outro? As condições de trabalho e os ganhos salariais foram, ao longo do período, sempre os piores possíveis. As razões, portanto, para a inquietação operária não mudaram. As máquinas de poder também continuaram sendo, essencialmente, as mesmas. O que houve foi um aprendizado, tanto de trabalhistas como de comunistas, acerca das possibilidades e limitações da luta social em um arranjo complexo como o que vigia no Brasil.

Movimentar-se no interior do laço Estado-Empresa-Sindicato-Trabalhadores implicou em concessões e acordos que respondiam às condições mutantes do jogo como interação estratégica. Isto, por vezes, impôs custos altos, como no caso que foi capturado de forma, digamos, elegante pela Folha Capixaba, ao reconhecer o que chamou de "Mal-estar entre os ferroviários". Os dirigentes foram preservados no discurso, mas não deixou de ser possível expressar a insatisfação da base. Rompido o equilíbrio precário, novas soluções foram dadas, o que nos mostra a relevância do papel exercido pelas elites dirigentes. Desta forma, a construção da classe trabalhadora como classe nunca foi produto apenas da cooptação, do corporativismo, das dinâmicas internas das suas elites e da cultura de classe. Foi e é uma combinação complexa, histórica entre tais elementos. 


\section{REFERÊNCIAS}

\section{Fontes primárias}

30\% conseguiram os ferroviários: Vale custou mas cedeu. Folha Capixaba, Vitória, 31 jan. 1959, p. 1.

COUTINHO, Lourival. Os ferroviários na luta de emancipação nacional. Folha Capixaba, Vitória, 5 jul. 1958, p. 5.

ELEIÇÃO na Cia. V. R. D.; exemplo de democracia. Folha Capixaba, Vitória, 21 nov. 1959, p. 8.

EM PERIGO a previdência social. Folha Capixaba, Vitória, 4 fev. 1961, p. 3.

FARIA, Boécio Pache de. O destino do Sindicato dos Ferroviários. Folha Capixaba, Vitória, 23 fev. 1957, p. 4.

MAL ESTAR entre os ferroviários. Folha Capixaba, Vitória, 25 mai. 1957, p. 2.

PAULINO, Geraldo. As eleições de 3 de outubro e a responsabilidade dos ferroviários. Folha Capixaba, Vitória, 23 ago. 1958, p. 3.

REALIZAÇÃO no Espírito Santo de um Congresso da Previdência. Folha Capixaba, Vitória, 11 mai. 1957, p. 5.

SANTANA, Manoel. Pleiteiam aumento de salários os ferroviários da Vitória-Minas. Folha Capixaba, Vitória, 13 fev. 1960, p. 6. Coluna Sindical.

TRIBUNAL SUPERIOR ELEITORAL (Brasil). Dados estatísticos. $4^{\circ}$ volume, eleições federais, estaduais, realisadas em 1958, e me confronto com anteriores. Rio de Janeiro: Departamento de Imprensa Nacional, 1961.

VITÓRIA espetacular da chapa Etevany-Alcyr nas eleições do Sindicato dos Ferroviários. Folha Capixaba, Vitória, 9 nov. 1957, p. 7.

\section{Fontes secundárias}

AMARAL, Maísa Maria Batista Prates do. Quando o camarada era mau: hierarquização e disciplinarização do trabalho na CVRD. In: GIL, Antonio Carlos Amador; PEREIRA, André Ricardo Valle Vasco; JESUS, Graziela Menezes de (Org.). Estudos de história política e das ideias. Vitória: LEHPI/UFES, 2014. p. 7-36.

BENEVIDES, Maria Victória Mesquita Benevides. A UDN e o udenismo: ambiguidades do liberalismo brasileiro. São Paulo: Paz e Terra, 1984.

BERTOCCHI, Charles Torres. Yes, agora nós temos um dono? Subordinação e resistência operária na etapa de reestruturação produtiva da Companhia Vale do Rio Doce. In: GIL, Antonio Carlos Amador; PEREIRA, André Ricardo Valle Vasco; JESUS, Graziela Menezes de (Org.). Estudos de história política e das ideias. Vitória: LEHPI/UFES, 2014. p. 74-36. 
BRAGA, Ruy. A política do precariado: do populismo ao lulismo. São Paulo: Boitempo, 2010.

CARDOSO, Lucian Rodrigues. Dilemas de Mario Gurgel: um trabalhista na Prefeitura de Vitória (1957 - 1958). In: GIL, Antonio Carlos Amador; PEREIRA, André Ricardo Valle Vasco; JESUS, Graziela Menezes de (Org.). Estudos de história política e das ideias. Vitória: LEHPI/UFES, 2014. p. 113-131.

ELSTER, John. Marxismo, funcionalismo $\mathrm{e}$ teoria dos jogos: argumentos em favor do individualismo metodológico. Lua Nova, São Paulo, n. 17, p. 163-204, jun. $1989 . \quad$ Disponível em: <http://www.scielo.br/scielo.php?script=sci_arttext\&pid=S0102-64451989000200009>. Acesso em: 16 jun. 2016.

FERREIRA, Jorge. O imaginário trabalhista: getulismo, PTB e cultura popular 19451964. Rio de Janeiro: Civilização Brasileira, 2005.

GOMES, Angela Maria de Castro. A invenção do trabalhismo. Rio de Janeiro: FGV, 2005 .

GOMES, Dino Oliveira. A práxis do guerreiro: a história de Antonio Ribeiro Granja. Brasília: Fundação Astrojildo Pereira, 2006.

GRANDSON, Douglas Edward Furness. As representações sobre a CVRD e a campanha do petróleo em A Gazeta, 1948. 100 f. 2014. Monografia (Graduação em História) - Universidade Federal do Espírito Santo, Centro de Ciências Humanas e Naturais, Departamento de História, Vitória, 2014. Disponível em: $<$ http://lehpi.ufes.br/sites/lehpi.ufes.br/files/field/anexo/douglas_mono.pdf $>$. Acesso em: 27 mar. 2015.

GRANDSON, Douglas Edward Furness. Entre o Amplo e o específico: mecanismos de controle sobre os trabalhadores da CVRD de 1959-1961. Revista Intellectus, Jaguariúna, v. 4, n. 36, p. 33-52, 2016. Disponível em: <http://www.revistaintellectus.com.br/DownloadArtigo.ashx? codigo=624>. Acesso em: 20 mar. 2017.

GRANJA, Antonio Ribeiro. Antonio Ribeiro Granja: depoimento [jul. 2012]. Entrevistador: André Ricardo Valle Vasco Pereira. Vitória: UFES, 2012. 1 arquivo mp3.

HISTÓRIA da Câmara. Nova Era: Câmara de Vereadores, 2017. Disponível em: $<$ http://www.cmne.mg.gov.br/site/index.php?option=com_content\&view=article\&id=5 9\&Itemid=75>. Acesso em: 20 mar. 2017.

IANNI, Octávio. A crise dos paradigmas na sociologia. Revista Crítica de Ciências Sociais, Coimbra, n. 32, p. 195-215, jun. 1991. Disponível em: $<$ https://poderedesenvolvimentolocal.files.wordpress.com/2011/02/octavio_ianni__a_crise_de_paradigmas_na_sociologia.pdf>. Acesso em: 16 jun. 2016. 
JOELSONS, Paula. AMFORP em Porto Alegre (1928-1959): multinacional norteamericana de eletricidade e o papel do gerente geral J. E. L. Millender. 2014. $128 \mathrm{f}$. Dissertação (Mestrado em História) - Programa de Pós-Graduação em História da Faculdade de Filosofia e Ciências Humanas da Pontifícia Universidade Católica do Rio Grande do Sul, Porto Alegre, 2014. Disponível em: <http://repositorio.pucrs.br/dspace/handle/10923/6823>. Acesso em: 18 jun. 2016.

MICHELS, Robert. Sociologia dos partidos políticos. Brasília: Editora Universidade de Brasília, 1982.

MINAYO, Maria Cecília de Souza. De ferro e flexíveis: marcas do Estado empresário na subjetividade operária. Rio de Janeiro: Garamond, 2004.

OLIVEIRA, Marlon Pittol de. Partido Comunista do Brasil na Câmara Municipal de Vitória: leituras e propostas. In: GIL, Antonio Carlos Amador; PEREIRA, André Ricardo Valle Vasco; JESUS, Graziela Menezes de (Org.). Estudos de história política e das ideias. Vitória: LEHPI/UFES, 2014. p. 352-370.

OLSON, Mancur. A lógica da ação coletiva. São Paulo: Edusp, 1999.

PANEBIANCO, Ângelo. Modelos de partido: organização e poder nos partidos políticos. São Paulo: Martins Fontes, 2005.

PEREIRA, André Ricardo Valle Vasco. Conflito de discursos na greve de 1948 na Companhia Vale do Rio Doce. In: CAMPOS, Adriana P.; VIANNA, Karulliny Silverol Siqueira; MOTTA, Katia Sausen da; LAGO, Rafaela Domingos (Org.). Memórias, traumas e rupturas. Vitória: LHPL/UFES, 2013a. p. 1-15.

PEREIRA, André Ricardo Valle Vasco. Espremeram tudo! Modernidade e tradição na memória de um ex-funcionário da Companhia Vale do Rio Doce. História Oral, Rio de Janeiro, v. 16, n. 1, p. 209-233, jan.-jun. 2013b. Disponível em: $<$ http://revista.historiaoral.org.br/index.php?journal=rho\&page $=$ article \&op $=$ view $\&$ path $\% 5 \mathrm{~B} \% 5 \mathrm{D}=280 \&$ path\%5B \%5D=311>. Acesso em: 6 jun. 2016.

PEREIRA, André Ricardo Valle Vasco. Que os homens não enganem os homens: a greve de 1948 na Companhia Vale do Rio Doce. In: GIL, Antonio Carlos Amador; PEREIRA, André Ricardo Valle Vasco; JESUS, Graziela Menezes de (Org.). Estudos de história política e das ideias. Vitória: LEHPI/UFES, 2014. p. 393-413.

PEREIRA, André Ricardo Valle Vasco. Teoria e Metodologia em Historia: o tratamento das fontes. Espírito Santo: SEAD/UFES, 2015.

PRZEWORSKI, Adam. Capitalismo e social democracia. São Paulo: Companhia das Letras, 1989.

RAMALHO, José Ricardo. Estado-patrão e luta operária: o caso da FNM. Rio de Janeiro: Paz e Terra, 1989.

SILVA, Marta Zorzal e. A Vale do Rio Doce na estratégia do desenvolvimento brasileiro. Vitória: EDUFES, 2004. 
SKIDMORE, Thomas. Brasil: de Getúlio a Castelo. 8. ed. Rio de Janeiro: Paz e Terra, 1982.

WEFFORT, Francisco. O populismo na política brasileira. 5. ed. Rio de Janeiro: Paz e Terra, 2003. 